Monatsschrift für Geburtshülfe u. Gynäkologie 1912;35:535-537

\title{
Richard Frommel †
}

\section{- 6. April 1912. -}

Unter der Schar wissensdurstiger Jünglinge, welche Carl Schröders meteorgleich erstrahlende Persönlichkeit an sich fesselte, trat Richard Frommel alsbald markant hervor. Aus glücklichsten Familienverhältnissen hervorgegangen, war der reichbegabte junge Arzt, geboren am 15. Juli 1854 in Augsburg, nach einer in froher Lebenslust und in behaglich ausgereiftem Studium zurückgelegten Universitätszeit 1879 an der Berliner Frauenklinik als Assistent eingetreten. Erfüllte ihn Schröders faszinierende Persönlichkeit mit hoher Begeisterung, fühlte er sich durch seinen treu verehrten Lehrer zu ernster eigener Arbeit angeregt, erfüllte sich schnell sein 536

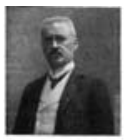

firmm $h$ Richard Frommel $\dagger$.

Sinnen und Trachten mit der vor ihm neu erstehenden Wissenschaft, so nahm ihn andererseits das Leben der Großstadt, die hohe Zeit politischer Entwicklung des jungen Reiches voll gefangen. Hier fühlte er auf dem Gebiete der von ihm erwählten wissen-schaftlichen Disziplin, hier im politischen und gesellschaftlichen Leben die mächtig vorwärtsstrebenden Antriebe, die ihm Sinn und Herz gefangen nahmen. Wie oft hat er es rückhaltlos bekannt, daß ihm in diesen Jahren erst der Wert des Lebens zu vollem Bewußtsein gekommen! Die Zeit beschaulichen Genießens war vorüber, er erkannte die belebende Kraft der Arbeit und ergriff be-geistert die Gelegenheit, seine eigenen reichen Kräfte zu entfalten. 1882 kehrte er nach München zurück, habilitierte sich und gewann alsbald nicht nur dureh den Ernst seines Strebens, die geschärfte Beobachtungsgabe, sein operatives Können, sondern auch durch die bestrickende Art seiner Betätigung als Arzt und Kollege festen Grund als Lelirer und als Praktiker. Als Zweifel Erlangen mit Leipzig vertauschte, war Frommel der Kandidat für die fränkische Hoch-schule. Hatte er dort in treuer Pflichterfüllung seinen akademischen Pflichten genügt, dann zogen ihn die glücklichen Eamilienverhält-nisse, die ihm München bot, in den Ferien dorthin und in die Berge, an die oberbayerischen Seen. Dort fand er stets Zeit und Be-friedigung in der Laboratoriumarbeit, zu welcher er im Getriebe des Semesters in Erlangen nicht durchdringen konnte. In diesem vielversprechenden Lebensgang traf ihn das Mißgeschick schwerer Erkrankung: er mußte seine Arbeit auf ein sehr geringes Maß be-schränken, langwierige Kuren durchmachen, die jede intensive Tätigkeit ausschlossen! Seine unerschütterliche Konsequenz wurde belohnt: er genas! Da verleidete ihn ein Konflikt über akademische Angelegenheiten das Amt und den Aufenthalt in der ihm lieb gewordenen Stellung. Mit der ihm eigenen Energie ver-zichtete er nicht nur auf jegliche Beziehung zum Staatsdienst, sondern auch zur ärztlichen Tätigkeit. Er zog sich zurück auch aus den Kreisen seiner akademischen Freunde, um voll seiner Pamilie und seinen sportlichen Neigungen zu leben. Mit innigem Bedauern mußten wir zusehen, wie er selbst aus 
einer unter den glücklichsten Auspizien begonnenen wissenschaftlichen Laufbahn ausschied und ohne Bedauern auf die ihm winkenden Erfolge seiner Arbeit ver-zichtete!

Mit unerbittlicher Konsequenz ist auch Richard Frommel be-schieden gewesen, was unter diesen Umständen unabwendbar ist. Seine ersten mehr kasuistischen Beiträge, seine experimentellen Arbeiten über die Innervation des Uterus, über die Milchsekretion

Richard. Frommel †.

537

u. a. werden bestehen bleiben, der fruchtbare Gedanke, unsere Fachliteratur zu sammeln, werden Frommels Namen in der Ge-schichte unseres Faches unvergänglich festhalten. Die

Frommelschen Jahresberichte bilden den Grundstock der Bücherei eines jeden, der sich literarisch betätigen will. Aber seine Persönlichkeit ist schon zu seinen Lebzeiten dem Auge und dem Bewußtsein der jüngeren Generation entschwunden: sein dahin zielender Wunsch ist nur zu schnell in Erfüllung gegangen!

Und dabei war er einer der lebensfrohsten Genossen, der sich im persönlichen Verkehr aller Herzen gewann. In den ersten Vereinigungen der Deutschen Gynäkologischen Gesellschaft nahm er nicht nur ernsten und nachhaltigen Anteil an den Ver-handlungen; um ihn scharten sich des Abends die jungen Kreise und ließen sich von seinem sprühenden Humor fesseln und festhalten. Späterhin trat der scharfe Sarkasmus, den er früher glücklich zurückgedrängt, mehr und mehr hervor. Aber wenn er Jahr für Jahr mit Rosthom, Sänger, Chrobak, mit W. A. Freund und mir im frühen Frühjahr in Karlsbad zusammentraf, dann kehrte er unverhüllt seine glücklichen und liebenswerten Herzens-eigenschaften hervor, die ihm unser ganzes Herz gewannen. Er war nicht nur ein faszinierender Kamerad, er besaß ein ernstes und viel umfassendes Wissen. Seine scharfe Kritik übte er auf Grund vollwertiger Kenntnisse und Beobachtungen. Wir konnten immer wieder nur laut beklagen. daß er jeder Versuchung, zu schaffender Arbeit zurückzukehren, wider stand!

So wird Frommels Name wohl festgehalten bleiben - seine so reich mit den glücklichsten und schönsten Eigenschaften und Fähigkeiten begabte Gestalt lebt schon in den jetzt an der Arbeit stehenden Generationen nicht mehr fort - mit uns, seinen Alters-genossen und den noch älteren wird das Bild seiner Persönlichkeit verschwinden!

Tief bewegt stehen wir an der Urne, die seine Asche birgt: Richard Frommel war einer der besten unter uns!

A. Martin. 